Udawatta, C.S., Devapriya, K.A.K., Gowsiga, M. and Thatshayini, P., 2019. An investigation into value addition concept correlated to facilities management. In: Sandanayake, Y.G., Gunatilake, S. and Waidyasekara, A. (eds). Proceedings of the $8^{\text {th }}$ World Construction Symposium, Colombo, Sri Lanka, 8-10 November 2019, pp. 56-65. DOI: doi.org/10.31705/WCS.2019.6. Available at: https://2019.ciobwcs.com/papers

\title{
AN INVESTIGATION INTO VALUE ADDITION CONCEPT CORRELATED TO FACILITIES MANAGEMENT
}

\author{
C.S. Udawatta ${ }^{1}$, K.A.K. Devapriya ${ }^{2}$, M. Gowsiga ${ }^{3}$ and P. Thatshayini ${ }^{4}$
}

\begin{abstract}
The purpose of this research is to enable Facilities Management (FM) decision makers to identify key FM interventions that add value to the organisations and to manage a successful implementation and to measure the outputs. This study inaugurated with literature review, and then a preliminary survey was carried out to validate the data gathered from the literature review. To inform the findings reported in this paper data was collected through semi structured interviews with expert from different industrial backgrounds. Empirical finding shows that most industrial professions think they should apply the concept of Adding Value in daily practice but there are constraints such as resistance from top management, limitations within the hierarchy, workload factor etc. Many experts identified that identifying a particular added value and the part FM played in is extremely complex and momentarily difficult. And the most acceptable interventions which were identified through interviews are changing the physical environment, changing the facilities services and strategic advice and planning. All the interviewees agreed that they only use Key Performance Indicators (KPIs) to measure the performance of facility related activities.
\end{abstract}

Keywords: Added Values; Facilities Management; Interventions; Key Performance Indicators.

\section{INTRODUCTION}

Analysing what is 'value' has long been a challenge in research and practice in service industries and as a concept, it has numerous meanings and usages (Anderson and Narus, 1998). In a higher level of generalisation, it outlined as the trade-off among benefits ("what you get") and sacrifices ("what you give") in a market exchange (Zeithaml, 1988). Delivering a superior value requires maximising the benefits and minimizing the sacrifices for customers within their relationship with suppliers (Ulaga and Chacour, 2001). Along with that, nowadays value becoming an important aspect and specifically, in the FM field, value is commonly based on economic rules of thumb. Value is produced when monetary value is added like lesser expenses or higher incomes to client organisation (Jensen, 2005). It can be viewed as the keystone of FM due to its activities are used as inputs into the client's resource-integrating and value creating activities as

\footnotetext{
${ }^{1}$ Department of Building Economics, University of Moratuwa, Sri Lanka, chathuranga.udawatta@gmail.com

${ }^{2}$ Department of Building Economics, University of Moratuwa, Sri Lanka, kakdevapriya@uom.lk

${ }^{3}$ Department of Building Economics, University of Moratuwa, Sri Lanka, gowsigam@uom.lk

${ }^{4}$ Treats Holdings Ltd., Acton, London, pthatsha@gmail.com
} 
clearly described in the value chain of (Porter and Advantage, 1985) where FM is part of the organisations' infrastructure. Recently, companies have paid more attention on performance measurement and performance is considered as a key competitive matter (Tranfield and Akhlaghi, 1995). There is a wide range of choices available to measure FM performance, reflecting the varied nature of the field. Hronec's (1993) emphasises establishing performance measures as a vital sign of an organisation, showing how well activities within a process or the outputs of a process achieve a specific goal. The structure of the paper begins with a review of literature related to key concepts of the study. Next it presents the method used in achieving the aim of the study and finally it presents the discussion on research findings together with conclusions and the recommendations.

\section{LITERATURE REVIEW}

\subsection{The Facilities Management Value MaP}

Recently, there has been a growing interest in the value construct and its significance for business success (Woodside et al., 2008). One of the first manifestations of the new focus on added value in FM was the establishment of a Nordic FM work group in 2006 to 'Highlight the added values for the core business provided by FM' (Jensen, et al., 2013). Value, to the customer, is benefits received for sacrifices given. Benefits refer to needs and wants and are what the customer seeks to buy, whereas sacrifices have both monetary and non-monetary components (Berry, 2009). Lindhom (2008) defines the added value as the value of the product reduced by the value of the resources used during the process, which leads to added exchange value by reducing cost and increasing efficiency. Furthermore, the FM Value Map can be used in general to provide a better understanding of the value and contributions of FM, for instance by FM organisations in the dialogue with their customers (Jensen, 2010). The generic version of the FM Value Map by Jensen (2010) is shown in Figure 1.

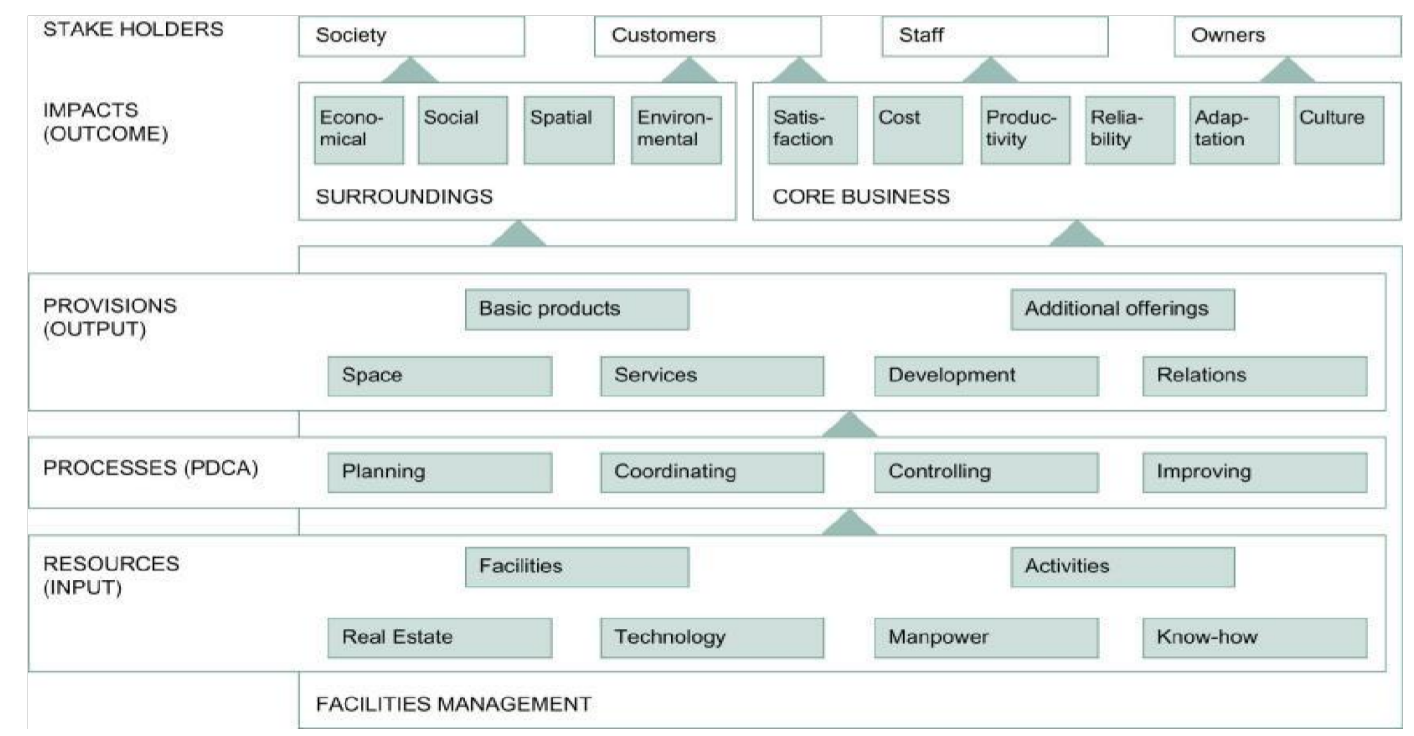

Figure 1: FM Value Map (Source: Jensen, 2010)

This is a conceptual framework to understand and explain the different methods in which FM can produce value to core business and to the surroundings for the benefits of multiple stakeholders together with owners, staff, customers and society. It maps the resources used by FM as inputs into the internal processes to produce outputs like space, services, 
development and relations, and the impacts the provisions from FM can have on core business in terms of satisfaction, cost, productivity, reliability, adaption, and culture, and on the surroundings in terms of economic, social, spatial and environmental aspects and uses a standard logic model (input-process-output) to specify the possible effects to different stakeholders (Jensen, 2010). Accordingly, the FM value map is for adopting a knowledge management approach, with a knowledge focus foundation, for FM that carefully considers how information can be utilised (gathered, captured, stored, retrieved and applied) to build capability and the knowledge of the individual, to add value to the organisation (Then and McEwan, 2004).

\subsection{FACILITIES MANAGEMENT INTERVENTIONS}

Coenen et al. (2012) developed a typology called "Interventions" or "Decisions on type of change", that can be applied to the FM context. The typology categories FM interventions to six types such as changing the physical environment, changing facilities services, changing the interface with core business, changing the supply chain, changing the internal processes and strategic advice and planning

\subsubsection{Changing the Physical Environment}

The physical environment is key to FM. It includes buildings, internal and external spaces, technical services (installations), indoor climate, fitting out, furniture, workplaces, technology, artwork and ambience. Typical examples of changing the physical environment include rebuilding, refurbishment or adaptive re-use, changing workplace layout, moving to another location and changing appearance.

\subsubsection{Changing Facilities Services}

Facilities services are the operational FM activities and few interventions related to the facilities are:

- Changing the maintenance approach from being mostly reactive to being more proactive by focusing on preventive maintenance to improve the facility condition.

- Changing the indoor climate monitoring to improve thermal and air comfort.

- Changing the monitoring and management of energy to reduce energy consumption.

- Changing the gardening of green areas to organic gardening without any use of pesticides to reduce the negative impact on environment

- Changing the workplaces with more flexible furniture to increase ergonomic quality and adaptability to individual work styles.

- Changing the facilities and providing the users with the opportunity to engage in sport and fitness activities in the corporate building

- Changing the monitoring of corporate facilities by installing CCTV surveillance to increase safety and security

- Changing the environmental management to engage the users more in reducing the negative environmental impact in relation to energy and waste.

\subsubsection{Changing the Interface with Core Business}

FM is normally established as a separate function, when organisations reach a certain size and complexity. The interface between the core business and FM is defined specifically 
in each organisation and is not static. If the FM function is successful, in many cases it will intensify its area of responsibility. This is often part of a centralization of the responsibility from several parts of the core business organisation to the FM function.

\subsubsection{Changing the Supply Chain}

In most cases FM is organized as an amalgamation of an in-house FM function and a number of external providers of facility services, which constitute a FM supply chain. Changes in the supply chain are principally changes in the delivery process. However, but they also often have consequences for the incentives for different parties and the management of the mutual relationships between the parties.

\subsubsection{Changing the Internal Processes}

This is about increasing the efficiency of operational processes within a specific organisation without necessarily changing either the product or the supply chain. The organisation can be in-house or an external FM provider. A lot of concepts aimed at increasing productivity and process efficiency, for instance Total Quality Management, Business Process Re-engineering, Benchmarking and Lean Management within management theory and practice. In such concepts, typical elements are eliminating waste, applying new technological solutions and optimising the workflow.

\subsubsection{Strategic Advice and Planning}

Strategic advice and planning are indispensable elements in the strategic and tactical activities of FM. The FM taxonomy of Jensen et al. (2008), includes some products at a strategic and tactical level, including a number of central functions with sub-products mentioned in parentheses such as sustainability, quality, risk and identity. A typical area of strategic advice from FM to top management relates to the development of a long-term strategy for the corporate property portfolio. This requires a profound and up-to-date understanding of the overall corporate strategy to determine the future demand for property, and close dialogue with the evaluation of options, scenarios and proposals concerning the future supply of property.

\subsection{Performance Measurement Models USED in FACILITIES MANAGEMENT}

Various models were developed to measure the performance of organisations, which could include Balanced Scorecard (BSC), Business Excellence Model (BEM), Capability Maturity Model (CMM), KPIs and etc. While these models come from various backgrounds, all of them have achieved significant success for the improvement of organisations' performance (Hamel and Prahalad, 1994). According to Bassioni et al., (2005) and Pitt and Tucker (2008) the revolution of performance measurement has spread into many disciplines, including FM. In contrast, Bassioni et al. (2005) have matched the application of various performance models and acknowledged a gap among knowledge and practice. Even though performance measurement is fresh to FM, certain researches have emerged in last years for the purpose of individual models in particular areas. For example, Shohet (2006) inspected the key indicators for the performance of maintenance management in healthcare facilities. In the following, four main performance models are introduced and discussed. 


\subsubsection{Balanced Scorecard (BSC)}

Conventional investment evaluation methods focus on financial quantity (Marsh and Flanagan, 2000). Contrasting traditional methods, Kaplan and Norton (2000) introduced the BSC to appraise whether a business is moving towards its strategic goal from four different perspectives such as financial, customer, internal business process, and learning and growth. In latest years the BSC has been slowly acknowledged by FM academics and specialists. For example, (Amaratunga and Baldry, 2000) used BSC to develop a conceptual framework for FM performance measurement in higher education assets. It has its defects like insufficiency of four perspectives while has gradually grownup popularity (Bassioni et al., 2005). Due to that, certain BSC models have gone beyond four perspectives.

\subsubsection{Business Excellence Model (BEM)}

European Foundation of Quality Management developed BEM in 1990 (Conti, 2007), BEM presents a cause-and-effect connection among enablers and results of business processes in an organisation based on nine criteria (Turner, 2008): results such as financial, customer satisfaction, people satisfaction, and impact on society, are achieved through acting on enablers such as leadership, policy and strategy, people management, resources, and processes management. This has progressively grown from the typical total quality management concept (Adebanjo, 2001). Accordance with this concept, several similar types of models were developed in other fields: e.g. Bassioni et al. (2005)'s conceptual framework for appraising business performance in construction.

\subsubsection{Capability Maturity Model (CMM)}

The Software Engineering Institute of Carnegie Mellon University recommended CMM as a software development evaluation standard in 1991 (Chrissis et al., 2003). CMM assists to pinpoint best exercises of an organisation which they presently reveal and in which they have to improve. A vital process zone mentions to a collection of linked actions to attain a set of goals that are regarded as important (Punch, 2005). In current years, the continuous representation was also included as one more path of assessment and enhancement. It enables an organisation to progressively improve processes corresponding to an individual process area(s). CMM has been initiated for several other disciplines along with the success in software sector. Compared to the wide acceptance of the BSC, BEM and KPI in construction, there are no explicit signs of the CMM-related models in the findings of Bassioni et al. (2005).

\subsubsection{Key Performance Indicators (KPIs)}

A performance indicator is a measure of performance (Fitz-Gibbon, 1990). KPIs are general indicators of performance that focus on critical aspects of outputs or outcomes (Chan and Chan, 2004). The KPI has been increasingly recognized by different industry sectors as a performance measurement system. Present days, some research works have been built on the KPI model for the FM discipline as an introduction. As sample, developed 11 performance indicators were developed by Shohet (2006) for planned maintenance of healthcare facilities, Hinks and McNay (1999) identified 23 performance indicators for managing various facilities. The usage of KPIs in a FM background can generate abundant benefits. It can assist to focus on managerial works regarding performance and can be used for FM service provider selection, communicating clear 
picture of required results and how which will be monitored and controlled (Loosemore and Hsin, 2001).

\section{RESEARCH METHODOLOGY}

The research aims to enable FM decision makers to identify key FM interventions that add value to the organisation and to manage a successful implementation and to measure the outputs through achieving the following objectives of the study. Research approach coordinates research activities and organises the data collection in order to achieve research aims (Thurairajah et al., 2006). Qualitative approach was used in this study in order to identify the most feasible performance measurement models applicable to FM. Additionally, actions were taken to develop a list FM interventions and performance measures to extract the interviewers' practices and opinion. The performance measurement and FM interventions were identified through the literature review. Prime data was gathered through the literature survey and then a preliminary interview was done to validate those collected data. Preliminary interviews were conducted with three industry experts who are currently engaged in industry high ranks using semi-structured questions. Table 1 reflects the summary of each interviewee with related to the practice, experience and the awareness of the concepts. the preliminary interview was performed by personal face to face interviews in order to increase the reliability of the data. Data collection was limited with the availability of seven industry experts related to the concept. Content analysis was used to analyse the collected data by using the NVivo 11.0 software. Interviewers' details are illustrated in Table 1.

Table 1: Details of the interviewers

\begin{tabular}{clll}
\hline Interviewee & \multicolumn{1}{c}{ Sector } & \multicolumn{1}{c}{ Designation } & \multicolumn{1}{c}{ Experience } \\
\hline IA & Goods Manufacturing & Premises Manager & $>20$ years \\
IB & FM Service Provider & Senior Facilities Executive & $>10$ years \\
IC & Apparel Sector & Senior Manager - Maintenance & 07 years \\
\hline
\end{tabular}

\section{RESEARCH FINDINGS AND ANALYSIS}

\subsection{Perceptions On VALUe ANd AdDed VALue}

All the respondents believe that value subject in FM should be given more professional consideration. Particularly in the FM field, value is commonly established on economic rules of thumb. Value is formed when financial value is added, i.e. fewer costs and more revenue for the organisation. Since, typically cost is prioritised and the technical approaches of FM, as per the interviewees, the profession still appears to be focused on a counting mind-set. But they all principally agreed that it is important a change of focus should happen from financial value in the direction of a holistic value of FM while formerly shareholder interests were the main perspective of value in the core functions of an organisation. IB believes that the Adding Value concept can be interpreted in large number of ways and associated with great diversity in different areas. He said that prioritizing different sorts of values tend to be extremely subjective and can be differ from organisation to organisation. He insisted that the value in FM rest on who get benefits from that particular added value and who bares the risks. Hence, it is vital to allow for the perceptions and curiosities of various stakeholders: organisation itself, suppliers, 
shareholders, customers and society. IA stated that to convince the top corporate levels about opportunities for added value, mainly, can be achieved by using strategic analysis and practical examples. IA and IB believes that adding value should mostly be considered at the strategic level, e.g. with the department or regional heads, not at the operational levels which comes under. IA went deeply and identified that FM is currently not a strategic matter in almost all of the organisations, He said top managements is not attentive to look in that way. The perception still going around is that FM is largely considered a tactical concern coming up from the organisational policies and strategies. He firmly believes FM should be a strategic concern that should work out by all the organisations themselves. FM is subject to the circumstances the organisation is going through under. IC mentioned that adding value is often considered at the strategic level with a focus largely on the cost as a value. But he believes that although all the planning and strategic directions have to be formulated at a strategic level (top managerial level), all the implementations should affect from a tactical level. According to IA different people have different perceptions on added value hence should be carefully discussed with people who are thorough in knowledge about added value which means the top-tobottom approach is necessary when formulating the value adding strategies for a successful implementation. IC had a different spectrum on this. He believes that this concept should be treated similarly in the all levels but in different methods:

1. Strategic level: primarily focuses on long term decisions, avoiding risks, satisfaction of shareholders and customers

2. Tactical level: focuses on budget alignments, satisfaction of employees and strategies to reduce costs.

3. Operational level: this level largely focuses on timely delivery of what is asked of them.

\subsection{BENEFITS AND LiMitations OF ADDED VALUE (AV)}

As per the interviewees concentrating on added value helps the organisation to focus on the impacts of FM and the expectations of strategic management. As all the interviewees believe speaking strategically is the language that top managements understand. It's significant to know the values which are important for the organisation and to ask the correct and measurable questions to recognize what the top management really need. He said that in a long-term view more often than not this can be not just simply resolving a current problem, which is the current practice in Sri Lankan FM context. IA said that it makes those who are responsible in making facilities-related decisions focus more on the strategic characteristics of FM and gives space for a more constructive discussion than focusing solely or more on cost. All of the respondents believed that there are definitely limitations, but few downsides compared with benefits. Considering about the limitations, they had different perspectives from each. IA said that added value is perceived differently by each people hence coming to a trade-off would be the major barrier going forward. According to him defining what value adding is proven to be difficult at times. For example, satisfaction can come up as financial satisfaction, customer satisfaction, employee satisfaction. As per him this is a major aspect that hinders the rise of FM in Sri Lankan context. IC mentioned that the main problem is that even though all the aspects with regard to the added value are identified by the top management, there is absolutely no or very less correlation between the departments which are responsible for preserving those added values. For an example in Sri Lankan context there is a myth the all the employee related aspects have to be handled under a Human Resources Department, even 
though to a certain extend it is true there are measures that comes under the other departments of an organisation which have direct impacts on employee satisfaction. So, without proper coordination a true success cannot be achieved specially because of the Sri Lankan organisation cultures. Another thing he noticed was that the added value is challenging to document. The things related with added value concept mostly cannot be measured immediately, for example in financial terms. Added value largely involves with feelings and subjective perceptions hence this can be subjective to a certain degree and it can be extremely difficult to document.

\subsection{FACILITIES MANAGEMENT INTERVENTIONS}

As per the interviewees, after classifying the interventions according the findings of the literature review regarding the FM interventions, all were agreeable and all can be categorized into the six factors identified. The results are briefly presented in Figure 2. The most mentioned interventions are changing the physical environment, changing the facilities services and strategic advice and planning. Findings were entered to the NVivo 11.0 software and analysis was done using generated nodes and cognitive maps.

\begin{tabular}{|c|c|c|}
\hline 1 Name & 8 Sources & References \\
\hline$\square \bigcirc$ Facilities Management Interventions & 0 & 0 \\
\hline$\boxminus$-. Facilities Management intervention types & 3 & 3 \\
\hline Changing the physical environment & 3 & 3 \\
\hline Changing facilities services & 2 & 2 \\
\hline Strategic advice and planning & 2 & 2 \\
\hline Changing the internal processes & 1 & 1 \\
\hline Changing the interface with core business & 1 & 1 \\
\hline Changing the supply chain & 1 & 1 \\
\hline
\end{tabular}

Figure 2: Coding structure for facility management interventions

\subsection{Performance Measurement}

Surprisingly all the interviewees agreed that they only use KPIs to measure the performance of facility related activities. IA mentioned that performance measurement is new to FM context in Sri Lanka hence there is a gap between knowledge and actual practice. All agreed that even KPIs are used to set benchmarks for relatively few of the functions coming under their respective departments, largely maintenance and health \& safety. As shown in Figure 3 findings were inserted to the NVivo 11.0 software and analysis was done based on the generated nodes and cognitive maps.

\begin{tabular}{|c|c|c|}
\hline Name & 8 Sources & $\bar{F}$ References \\
\hline$\square \bigcirc$ Performance Measurement Models & 0 & 0 \\
\hline Đ Performance measurement models in practice & 3 & 3 \\
\hline Key Performance Indicators & 3 & 3 \\
\hline
\end{tabular}

Figure 3: Coding structure for performance measurement models 


\section{CONCLUSIONS AND RECOMMENDATIONS}

At the end of the empirical findings, it is clear that that concept of adding value is emerging in Sri Lankan business context as more people become aware of it, more people tend to seek added value to optimize the processed within their organisations could be identified through in-depth discussions with respondents. The interviews with experts showed that most practitioners think they should apply the concept of Adding Value in daily practice but there are constraints such as resistance from top management, limitations within the hierarchy, workload factor, etc. Many experts identified that identifying a particular added value and the part FM played in is extremely complex and momentarily difficult. And the most acceptable interventions which were identified through interviews are changing the physical environment, changing the facilities services and strategic advice and planning. All the interviewees agreed that they only use KPIs to measure the performance of facility related activities. This suggested value map helps the FM decision makers to where they can improve and work on by proving a framework on value adding management. It enables the decision makers to appropriately consider and implement FM interventions and they can use the identified tools using the PDCA cycle to ensure the value adding management model is a successful one. Also, this enables the FM decision makers to convince the top managements to give a strategic perspective to FM and to convince them to use this as a more strategic-centred profession rather than a cost-centred one. The developed FM value adding framework can use as a step by step process to implement appropriate interventions and add value to the organizations. The introduced tools to support successful implementation of the interventions throughout the PDCA cycle can use by the practitioners as they are easy to work with will give maximum possible outcomes as expected to enhance the organizational performance.

\section{REFERENCES}

Adebanjo, D., 2001. TQM and business excellence: is there really a conflict?. Measuring Business Excellence, 5(3), pp.37-40.

Amaratunga, D. and Baldry, D., 2000. Assessment of facilities management performance in higher education properties. Facilities, 18(7/8), pp.293-301.

Anderson, J.C. and Narus, J.A., 1998. Business marketing: understand what customers value. Harvard Business Review, 76, pp.53-67.

Bassioni, H., Price, A. D. F. and Hassan, T. M., 2005. Building a conceptual framework for measuring business performance in construction: an empirical evaluation, Construction Management and Economics, 23(5), pp.495-507.

Berry, L., 2009. Competing with quality service in good times and bad. Business Horizons. 52(4), pp.309317.

Brackertz, N., 2006. Relating physical and service performance in local government community facilities. Facilities, 24(7/8), pp.280-291.

Chan, A. P. C. and Chan, A. P. L., 2004. Key performance indicators for measuring construction success, Benchmarking. An International Journal, 11(2), pp.203-221.

Chrissis, M.B., Konrad, M. and Shrum, S., 2003. CMMI guidlines for process integration and product improvement. Addison-Wesley Longman Publishing Co., Inc.

Coenen, C., Alexander, K., Kok, H. and Jensen, P., 2012. FM as a value network: exploring relationships amongst key FM stakeholders. The added value of facilities management: concepts, findings and perspectives. Lyngby: Polyteknisk Forlag.

Conti, T. A., 2007. A history and review of the European Quality Award Model. The TQM Magazine, 19(2), pp.112-128. 
Fitz-Gibbon, C.T. ed., 1990. Performance indicators (Vol. 2). Multilingual Matters.

Hamel, G. and Prahalad, C. K., 1994. Competing for the Future Harvard Business. Boston: School Press.

Hinks, J. and McNay, P., 1999. The creation of a management-by-variance tool for facilities management performance assessment. Facilities, 17(1/2), pp.31-53.

Hronec, S., 1993. Vital Signs: Using Quality. Time and Cost Performance Measurements to Chart Your Company's Future. New York: Amacom.

Jensen , P., Nielsen, K. and Nielsen, S. B., 2008. Facilities Management Best Practice in the Nordic Countries - 36 cases, Centre for Facilities Management - Realdania Research, DTU Management Engineering: Technical University of Denmark.

Jensen, P.A., 2005. Value concepts and value based collaboration in building projects. In Designing Value: New directions in architectural management. Technical University of Denmark (DTU).

Jensen, P., 2010. The Facilities Management Value Map: a conceptual framework. Facilities, 28(3/4), pp.175-188.

Jensen, P.A., Sarasoja, A.L., Van der Voordt, D.J.M. and Coenen, C., 2013. How can facilities management add value to organisations as well as to society?. In Proceedings of the 19th CIB World Building Congress 2013 "Construction and Society", Brisbane, Australia, 5-9 May 2013. International Council for Building (CIB).

Kaplan, R. and Norton, D., 2000. Having trouble with your strategy? Then map it. Focusing Your Organization on Strategy - with the Balanced Scorecard, 49.

Lindholm, A., 2008. Identifying and measuring the success of corporate real estate management. Teknillinen korkeakoulu.

Loosemore, M. and Hsin, Y. Y., 2001. Customer-focused benchmarking for facilities management. Facilities, 19(13/14), pp.464-476.

Marsh, L. and Flanagan, R., 2000. Measuring the costs and benefits of information technology in construction. Engineering Construction and Architectural Management, 7(4), pp.423-435.

Pitt, M. and Tucker, M., 2008. Performance measurement in facilities management: driving innovation?. Property Management, 26(4), pp.241-254.

Porter, M. and Advantage, C., 1985. Creating and Sustaining Superior Performance. New York: Free press.

Punch, K. F., 2005. Introduction to social research: Quantitative and qualitative approach. $2^{\text {nd }}$ ed. SAGE Publications.

Shohet, I., 2006. Key performance indicators for strategic healthcare facilities maintenance. Journal of Construction Engineering and Management, 132(4), pp.345-352.

Then, D.S.S. and McEwan, A., 2004. Capturing knowledge from facilities management practices-Issues and Possibilities. Facilities Management and Maintenance, pp.251-263.

Thurairajah, N., Haigh, R. and Amaratunga, D., 2006. Leadership in construction partnering projects: Research methodological perspective., In ARCOM Doctoral Workshop on Public Private Partnerships/Private Finance Initiatives (PPP/PFI), Glasgow Caledonian University, UK.

Tranfield, D. and Akhlaghi, F., 1995. Performance measures: relating facilities to business indicators. Facilities, 13(3), pp.6-14.

Ulaga, W. and Chacour, S., 2001. Measuring customer-perceived value in business markets: a prerequisite for marketing strategy development and implementation. Industrial Marketing Management, 30(6), pp.525-540.

Woodside, A., Golfette, F. and Gibbert, M., 2008. Creating and managing superior customer value. Emerald Group Publishing.

Zeithaml, V.A., 1988. Consumer perceptions of price, quality, and value: a means-end model and synthesis of evidence. Journal of Marketing, 52(3), pp.2-22. 